\title{
FTO variant is not associated with osteoarthritis in the Chinese Han population: replication study for a genome- wide association study identified risk loci
}

\author{
Jin Dai ${ }^{1,2+}$, Pu Ying ${ }^{1,2+}$, Dongquan Shi ${ }^{1,2}$, Huacheng Hou ${ }^{1,2}$, Ye Sun ${ }^{1,2}$, Zhihong $\mathrm{Xu}^{1,2}$, Dongyang Chen ${ }^{1,2}$,
} Guoqiang Zhang ${ }^{3}$, Ming $\mathrm{Ni}^{3}$, Huajian Teng ${ }^{2}$, Yan Wang ${ }^{3^{*}}$ and Qing Jiang ${ }^{1,2^{*}}$

\begin{abstract}
Background: Osteoarthritis is the most prevalent form of arthritis worldwide and is the major cause of pain and loss of function in elderly people. A signal of the fat mass and obesity-associated (FTO) gene had been reported in a genome-wide association study of osteoarthritis. The FTO polymorphism (rs8044769) might exert its effect on osteoarthritis through obesity, because it was reported as a body mass index-associated single-nucleotide polymorphism. And replication studies showed inconsistent results for this association. Our present study is to check the association of rs8044769 with osteoarthritis and body mass index in Chinese Han population.

Methods: A case-control association study was conducted by using 890 osteoarthritis cases and 844 controls in Chinese Han population. rs 8044769 was genotyped in all subjects. Allelic and genotypic frequencies were compared between osteoarthritis cases and control subjects. Associations between rs8044769 and body mass index, and body mass index and osteoarthritis were also assessed.

Results: No significant difference was detected in genotype or allele distribution between osteoarthritis cases and controls $(P>0.05)$. Stratification by gender and body mass index revealed negative association between rs8044769 and osteoarthritis. We did not find any solid association between rs 8044769 and higher body mass index. Meanwhile, we demonstrated that higher body mass index (body mass index $\geq 25$ ) was associated with osteoarthritis.

Conclusion: Our present study suggested that rs8044769 was not associated with osteoarthritis susceptibility or higher body mass index, and higher body mass index was a risk factor for osteoarthritis in the Chinese Han population. We also proposed that stratification by clinical parameters was crucial to reduce false-positive result in OA association studies.
\end{abstract}

Keywords: FTO, Osteoarthritis, Obesity, Single nucleotide polymorphism, Body mass index

\section{Background}

Osteoarthritis (OA; OMIM 165720) is the most common degenerative disease of the joints among the elderly. Hip and knee OA are the main causes of pain, functional loss, and depressed quality of life in both developed and

\footnotetext{
*Correspondence: yanwang301@163.com; qingj@nju.edu.cn

${ }^{\dagger}$ Equal contributors

${ }^{3}$ Department of Orthopaedics, Chinese PLA General Hospital, 28 Fuxing Road, Beijing 100853, China

${ }^{1}$ The department of Sports Medicine and Adult Reconstructive Surgery,

Drum Tower Hospital, School of Medicine, Nanjing University, 321

Zhongshan Road, Nanjing 210009, Jiangsu, China

Full list of author information is available at the end of the article
}

developing countries. OA, like other complex chronic disease, develops through a combination of environmental and genetic risk factors [1].

Obesity has been consistently associated with an augmented risk of $\mathrm{OA}$, but its role in the progression of $\mathrm{OA}$ has not been well established. Both biomechanical and metabolic factors are likely to link obesity and OA. Biomechanical overload on joints can accelerate cartilage degeneration, while metabolic dysfunction caused by obesity may have a more severe influence on OA than body weight [2]. Recent studies showed adipose tissue could increase cartilage degeneration through a secretion 
of pro-inflammatory mediators and synergistic regulation with other inflammatory cytokines [3].

The fat mass and obesity-associated (FTO) gene encodes a 2-oxoglutarate-dependent nucleic acid demethylase. Its structure has been reported, but the exact function of this gene remains unknown [4,5]. Genetic studies have showed variants in FTO are associated with an increased body mass index (BMI) which is an obesity-related measurement in several studies [6-12]. A genome-wide association study (GWAS) named arcOGEN study had found that a FTO single-nucleotide polymorphism (SNP) rs8044769 was in the strongest association with female OA close to genome-wide significance $\left(P=6.85 \times 10^{-8}\right)$. This significance was degenerative after BMI adjustment, hinting that this FTO polymorphism may exert its influence on OA through obesity [13, 14]. The association was replicated in a study on North American Caucasians [15]. A study on Chinese Han population denied this association, but the subject number of the Chinese study was a little bit small [16]. Until now, the association between FTO and OA remains debatable.

Therefore, we evaluated the potential association of the FTO polymorphism (rs8044769) with OA in the Chinese Han population with more cases and controls. We also evaluated the association of this polymorphism with BMI because of the known effect of FTO on BMI.

\section{Methods}

\section{Subjects}

All patients were recruited from the department of Sports Medicine and Adult Reconstructive Surgery, Drum Tower Hospital, School of Medicine, Nanjing University and were diagnosed as having knee $\mathrm{OA}$ according to the previous study [17]. All the radio-graphics were estimated by the Kellgren/Lawrence grading system [18]. Other knee diseases like rheumatoid arthritis, post-traumatic or postseptic arthritis, and developmental dysplasia of the knee were excluded. We set the youngest age for the controls which is the same with the cases. The control subjects were consecutively enrolled at the Physical Examination Center, Drum Tower Hospital Affiliated to the Medical school of Nanjing University. They had no sign or symptom of arthritis or joint diseases. All the study populations were non-institutionalized Han Chinese living in or around Nanjing. This study was approved by the ethics review committee of the Nanjing University and conducted according to the Declaration of Helsinki principles. All participants were informed with letter of consent.

\section{BMI measure}

Height and weight were measured (without shoes and in light clothes) by medical technicians. BMI was calculated by taking a person's weight and dividing it by their height squared. Subjects were classified as underweight
$\left(\mathrm{BMI}<18.5 \mathrm{~kg} / \mathrm{m}^{2}\right)$, normal $\left(18.5 \mathrm{~kg} / \mathrm{m}^{2} \leq \mathrm{BMI}<25 \mathrm{~kg} / \mathrm{m}^{2}\right)$, overweight $\left(25 \mathrm{~kg} / \mathrm{m}^{2} \leq \mathrm{BMI}<30 \mathrm{~kg} / \mathrm{m}^{2}\right)$, and obese $\left(B M I \geq 30 \mathrm{~kg} / \mathrm{m}^{2}\right)$ set by the criteria of World Health Organization [19].

\section{Genotyping}

DNA was extracted from peripheral blood leukocytes using the NucleoSpin Blood QuickPure Kit (MACHEREYNAGEL GmbH \& Co. KG, Düren, German). The SNP was genotyped using the Taqman assay in an ABI 7500 system (Applied Biosystems, Foster City, CA, USA). Genotyping was done by laboratory personnel blinded to case status. Three percent of samples were duplicated, and the concordance rate was $100 \%$.

\section{Statistical analysis}

Characteristics of the OA and the control groups were evaluated by using chi-square and Mann-Whitney test. The Hardy-Weinberg equilibrium (HWE) of genotypes in OA and control groups was tested by using chisquare test. The differences of genotype and allele distributions were evaluated by using Chi-square test. The combined effect for the risk allele was evaluated by Mantel-Haenszel test. BMI among different genotypes of FTO polymorphism were compared using KruskalWallis test. The Potential associations between BMI and OA were evaluated by using unconditional logistic regression modeling. All $P$ value reported as statistical significance was set at $<0.05$. Odds ratio (OR) was calculated with $95 \%$ confidence interval $(95 \% \mathrm{CI})$. Calculations were performed using SPSS 12.5S (SPSS, Chicago, USA) or Stata 8.2 (Stata, College Station, TX, USA).

\section{Results}

The basic characteristics of the study population were showed in Table 1. On average, OA cases were older and had greater BMI than controls. Females were prevalent

Table 1 Characteristics of the osteoarthritis and control study population

\begin{tabular}{lll}
\hline Characteristic & Cases & Controls \\
\hline Sample size & 890 & 844 \\
Males (\%) & $226(25.28)$ & $681(80.69)$ \\
BMI (mean \pm SD) & $25.76 \pm 3.69$ & $24.91 \pm 3.04^{*}$ \\
$\quad$ Underweight (\%) & $8(0.89)$ & $12(1.42)$ \\
$\quad$ Normal weight (\%) & $400(44.94)$ & $422(50)$ \\
Overweight (\%) & $376(42.24)$ & $368(43.60)$ \\
Obese (\%) & $106(11.91)$ & $42(4.98)$ \\
Age (mean \pm SD) & $62.51 \pm 11.43$ & $54.07 \pm 11.60^{*}$ \\
\hline
\end{tabular}

$B M I$ body mass index $\left(\mathrm{kg} / \mathrm{m}^{2}\right), O A$ osteoarthritis, $K-L$ score Kellgren/Lawrence score

underweight, $\mathrm{BMI}<18.5$; normal, $18.5 \leq \mathrm{BMI}<25$; overweight, $25 \leq \mathrm{BMI}<30$; obese, $\mathrm{BMI} \geq 30$

${ }^{*} P<0.001$ for Mann-Whitney test as applicable between cases/controls 
Table 2 Genotype and allele frequencies of FTO polymorphism (rs8044769) in Han Chinese population

\begin{tabular}{|c|c|c|c|c|c|c|c|c|c|c|}
\hline \multirow[t]{2}{*}{ Subjects } & \multirow[t]{2}{*}{$N$} & \multicolumn{2}{|l|}{ Allele } & \multirow[t]{2}{*}{$P$ value } & \multirow[t]{2}{*}{$P_{\text {het }}$} & \multirow[t]{2}{*}{ OR $(95 \% \mathrm{Cl})$} & \multicolumn{3}{|l|}{ Genotype } & \multirow[t]{2}{*}{$P$ value } \\
\hline & & C (\%) & $\mathrm{T}(\%)$ & & & & CC (\%) & $\mathrm{CT}(\%)$ & ТТ (\%) & \\
\hline Cases & 890 & $1096(61.57)$ & $684(38.43)$ & 0.436 & & $0.947(0.825-1.086)$ & $333(37.41)$ & $430(48.32)$ & $127(14.27)$ & 0.438 \\
\hline Controls & 844 & $1061(62.85)$ & $627(37.14)$ & & & & $339(40.16)$ & $383(45.38)$ & $122(14.46)$ & \\
\hline \multicolumn{11}{|c|}{ Combined with another Chinese group } \\
\hline Cases & $890+1093$ & $1096+233(61.36)$ & $684+153(38.64)$ & $0.478^{*}$ & $0.745^{* *}$ & $0.958^{*}(0.849-1.079)$ & & & & \\
\hline Controls & $844+436$ & $1061+528(62.07)$ & $627+344(37.93)$ & & & & & & & \\
\hline
\end{tabular}

*P value and odds ratio were calculated by Mantel-Haenszel test, ${ }^{* *} P$ for heterogeneity

in the OA group. The mean age was $62.51 \pm 11.43$ years and mean BMI was $25.76 \pm 3.69 \mathrm{~kg} / \mathrm{m} 2$ in cases compared to $54.07 \pm 11.60$ years and $24.91 \pm 3.04 \mathrm{~kg} / \mathrm{m} 2$ in controls, respectively. Genotype and allele frequencies for FTO polymorphism were not significantly different between OA cases and controls (Table 2). We combined our data with the data from the previous Chinese study and found no association between the risk allele with OA (Table 2) [16]. We next examined potential association of rs8044769 with OA when stratified by gender and BMI. No significant difference was observed in any comparisons between OA cases and controls (Table 3).

Associations between rs8044769 and BMI were also evaluated. Genotype and allele frequencies for FTO polymorphism were not significantly different between overweight and obese cases and controls (Table 4). No significant associations were observed between overweight and obese cases and controls in females, males, OA cases and OA controls, respectively. We also compared BMI among different genotypes of rs8044769 in Han Chinese population. We found no significant difference of BMI among three genotypes of rs8044769. We then examined associations between rs8044769 and BMI in females, males, OA cases, and controls, respectively, and found no significant differences of BMI among three genotypes of rs8044769 (Table 5).

We last examined potential associations between BMI and OA (Table 6). Through the logistic regression modeling, we demonstrated a higher BMI (overweight and obese, $\mathrm{BMI} \geq 25$ ) was a risk factor for OA in the Chinese Han population (Additional files 1 and 2).

\section{Discussion}

In our study population, the mean age of OA patients is significantly higher than that of controls, and the females are significantly more prevalent in OA cases. The mean BMI in OA patients was significantly higher than that in controls, and the logistic regression analysis also showed that BMI was associated with OA. Our data conformed to the previous reports that age, female gender, and overload were risk factors for OA [20, 21].

The association of this FTO polymorphism (rs8044769) with OA was not replicated in the Chinese Han population. The previous GWAS found rs8044769 in FTO was one of the signals close to genome-wide significance for OA in a European population. Our results did not show any positive associations between rs8044769 and OA, even after stratification by gender and BMI. We combined our data with the data from another Chinese study and found no associations between the risk allele of rs8044769 and OA either.

The association of the FTO polymorphism (rs8044769) with BMI was not replicated in the Chinese Han population either. The previous studies showed that FTO was associated with BMI [6-12], and two of them referred to rs8044769 as BMI-associated SNP [11, 12]. In the association analysis of rs8044769 with BMI, we found no association between rs8044769 and BMI. And the BMIs

Table 3 Association of FTO polymorphism (rs8044769) with osteoarthritis when stratified by gender and BMI

\begin{tabular}{|c|c|c|c|c|c|c|c|c|c|c|}
\hline \multirow[t]{2}{*}{ Groups compared } & \multicolumn{3}{|c|}{ CC vs. other combined } & \multicolumn{3}{|c|}{ Tा vs. other combined } & \multicolumn{3}{|c|}{$\mathrm{C}$ allele vs. $\mathrm{T}$ allele } & \multirow{2}{*}{$\begin{array}{l}\text { All genotype } \\
P \text { value }\end{array}$} \\
\hline & $P$ value & OR & $95 \% \mathrm{Cl}$ & $P$ value & OR & $95 \% \mathrm{Cl}$ & $P$ value & OR & $95 \% \mathrm{Cl}$ & \\
\hline $\begin{array}{l}\text { Female cases }(n=665) \text { vs. controls } \\
(n=163)\end{array}$ & 0.802 & 0.956 & $0.673-1.36$ & 0.402 & 0.819 & $0.513-1.31$ & 0.801 & 1.03 & $0.805-1.32$ & 0.604 \\
\hline $\begin{array}{l}\text { Male cases }(n=225) \text { vs. controls } \\
(n=681)\end{array}$ & 0.160 & 0.799 & $0.584-1.09$ & 0.666 & 1.098 & $0.718-1.68$ & 0.222 & 0.878 & $0.702-1.09$ & 0.373 \\
\hline $\begin{array}{l}\text { Normal weight cases }(n=400) \\
\text { vs. controls }(n=422)\end{array}$ & 0.241 & 0.845 & $0.639-1.12$ & 0.831 & 1.04 & $0.706-1.54$ & 0.345 & 0.908 & $0.744-1.11$ & 0.494 \\
\hline $\begin{array}{l}\text { Overweight cases }(n=376) \\
\text { vs. controls }(n=368)\end{array}$ & 0.448 & 0.892 & $0.663-1.20$ & 0.742 & 0.934 & $0.621-1.40$ & 0.712 & 0.961 & $0.780-1.19$ & 0.623 \\
\hline $\begin{array}{l}\text { Obese cases ( } n=106) \text { vs. controls } \\
(n=42)\end{array}$ & 0.782 & 1.11 & $0.532-2.31$ & 0.616 & 1.32 & $0.450-3.85$ & 0.954 & 0.985 & $0.583-1.66$ & 0.790 \\
\hline
\end{tabular}


Table 4 Associations between FTO polymorphism and BMI when stratified by gender and OA status

\begin{tabular}{|c|c|c|c|c|c|c|c|c|c|c|}
\hline \multirow[t]{2}{*}{ Groups compared } & \multicolumn{3}{|c|}{ CC vs. other combined } & \multicolumn{3}{|c|}{ TT vs. other combined } & \multicolumn{3}{|c|}{ C allele vs. $T$ allele } & \multirow{2}{*}{$\begin{array}{l}\text { All genotype } \\
P \text { value }\end{array}$} \\
\hline & $P$ value & OR & $95 \% \mathrm{Cl}$ & $P$ value & OR & $95 \% \mathrm{Cl}$ & $P$ value & OR & $95 \% \mathrm{Cl}$ & \\
\hline $\begin{array}{l}\text { Total overweight and obese cases }(n=892) \\
\text { vs. controls }(n=842)\end{array}$ & 0.867 & 0.984 & $0.811-1.19$ & 0.901 & 1.012 & $0.778-1.33$ & 0.856 & 0.987 & $0.861-1.13$ & 0.983 \\
\hline $\begin{array}{l}\text { Overweight and obese cases }(n=423) \\
\text { vs. controls }(n=405) \text { in females }\end{array}$ & 0.835 & 0.971 & $0.734-1.28$ & 0.738 & 1.07 & $0.725-1.57$ & 0.750 & 0.968 & $0.794-1.18$ & 0.940 \\
\hline $\begin{array}{l}\text { Overweight and obese cases }(n=469) \\
\text { vs. controls }(n=437) \text { in males }\end{array}$ & 0.973 & 0.995 & $0.762-1.30$ & 0.882 & 0.972 & $0.670-1.41$ & 0.959 & 1.00 & $0.831-1.22$ & 0.985 \\
\hline $\begin{array}{l}\text { Overweight and obese cases }(n=482) \\
\text { vs. controls }(n=408) \text { in OA cases }\end{array}$ & 0.818 & 1.03 & $0.786-1.36$ & 0.966 & 1.01 & $0.692-1.47$ & 0.888 & 1.01 & $0.837-1.23$ & 0.967 \\
\hline $\begin{array}{l}\text { Overweight and obese cases }(n=410) \\
\text { vs. controls }(n=434) \text { in OA controls }\end{array}$ & 0.707 & 0.948 & $0.720-1.25$ & 0.886 & 1.03 & $0.701-1.51$ & 0.731 & 0.966 & $0.793-1.18$ & 0.931 \\
\hline
\end{tabular}

corresponding different genotypes of rs8044769 showed no significant difference.

There are several possible reasons for the negative association between rs8044769 and OA. The sample size of our study might be insufficient. But regarding the odds ratio of the risk allele in our data and the previous Chinese study, it is difficult to get a significant difference by enlarging sample size. The gender distribution was not matched in OA patients and controls. In our study the genotype distributions did not vary a lot between females and males, and no significant association was found after stratification by gender.

We think the ethnic difference might be an important reason for the negative result in both the association study between rs8044769 and OA and the association study between rs8044769 and BMI, as the allele frequency and genotype distribution rs8044769 were different between Chinese Han population and Caucasian population [13-16]. The negative association in our population cannot deny the association of rs8044769 with OA and BMI in other populations.

An extended study of the GWAS study revealed that the association between rs8044769 and OA was degenerated after stratification by BMI, and the association between rs8044769 and BMI was identified in this study [14]. There have been several reports for the association

Table 5 Comparison of anthropometric parameters among different genotypes of FTO polymorphism (rs8044769) in Han Chinese population

\begin{tabular}{|c|c|c|c|c|}
\hline \multirow[t]{2}{*}{ Items } & \multicolumn{3}{|c|}{ Genotype (mean \pm SD) } & \multirow[t]{2}{*}{$P$ value } \\
\hline & $\overline{C C}$ & $\mathrm{CT}$ & $\pi$ & \\
\hline BMI $\left(\mathrm{kg} / \mathrm{m}^{2}\right)$ & $25.35 \pm 3.37$ & $25.37 \pm 3.47$ & $25.27 \pm 3.33$ & 0.980 \\
\hline $\begin{array}{l}\text { BMl in females } \\
\left(\mathrm{kg} / \mathrm{m}^{2}\right)\end{array}$ & $25.37 \pm 3.70$ & $25.50 \pm 3.88$ & $25.46 \pm 3.86$ & 0.925 \\
\hline BMl in males $\left(\mathrm{kg} / \mathrm{m}^{2}\right)$ & $25.34 \pm 3.07$ & $25.26 \pm 3.06$ & $25.10 \pm 2.76$ & 0.797 \\
\hline BMI in cases $\left(\mathrm{kg} / \mathrm{m}^{2}\right)$ & $25.77 \pm 3.62$ & $25.78 \pm 3.79$ & $25.67 \pm 3.53$ & 0.946 \\
\hline $\begin{array}{l}\text { BMl in controls } \\
\left(\mathrm{kg} / \mathrm{m}^{2}\right)\end{array}$ & $24.94 \pm 3.08$ & $24.91 \pm 3.02$ & $24.86 \pm 3.07$ & 0.966 \\
\hline
\end{tabular}

$P$ values were analyzed using Kruskal-Wallis test between FTO and BMI [6-12], and two of them referred to rs8044769 as BMI associated SNP [11, 12]. So, we suspected that the association between rs8044769 and BMI may contribute to the association between this SNP and OA in the GWAS study. However, in our study, rs8044769 was not associated with BMI, and it might be another reason for the negative association between rs8044769 and OA.

From our data we cannot get a conclusion that FTO is not associated with BMI in Chinese population as the allele and genotype differences of rs8044769 do not equal to changes of FTO function or FTO expression. Some other genetic variants in FTO might be associated with BMI or OA in Chinese population, and further studies are needed to evaluate the association of FTO with BMI and OA.

The associations among rs8044769, BMI, and OA drew attentions to some concern on current GWAS results. Shortcomings like the imprecise phenotype definitions, chosen criterion, and limited study populations in the GWAS may lead to some false-positive association [22-25]. Stratification by clinical parameters such as $\mathrm{BMI}$ can reduce the risk of false-positive result, but the cost-effectiveness is uneconomical in the primary study. Future studies in OA genetics are required using more accurate phenotype definition, improved case/control selecting standardization, and increased sample sizes as well as extending studies to different populations. In

Table 6 Association between high body mass index and osteoarthritis

\begin{tabular}{|c|c|c|c|c|c|c|}
\hline \multirow[t]{2}{*}{ Groups } & \multicolumn{2}{|l|}{$\mathrm{N}$} & \multicolumn{2}{|c|}{ Unadjusted } & \multicolumn{2}{|c|}{ Adjusted $^{\mathrm{a}}$} \\
\hline & Cases & Controls & $\overline{O R}$ & $95 \% \mathrm{Cl}$ & $\mathrm{OR}$ & $95 \% \mathrm{Cl}$ \\
\hline Normal & 400 & 422 & & & & \\
\hline $\begin{array}{l}\text { Overweight } \\
(25 \leq \mathrm{BMl}<30)\end{array}$ & 376 & 368 & & & & \\
\hline Obese (BMI $\geq 30$ ) & 106 & 42 & $1.08^{* *}$ & $1.05-1.11$ & $1.06^{*}$ & $1.02-1.10$ \\
\hline
\end{tabular}

$P$ values were analyzed using unconditional logistic regression

${ }^{*} P=0.006 ; * * 0<0.001$

${ }^{\mathrm{a}}$ Adjusted for age and gender 
addition, functional characterization and studies of the risk loci can help us understand better of the OA genetics.

Our results were consistent with a previous study in Chinese population and had enlarged studied subjects. We also conducted a meta-analysis together with the previous study in Chinese population to offer a solid evidence that rs8044769 of FTO was not associated with OA risk or BMI in Chinese population. By comparing with the result of the extended study of the GWAS study, we proposed that stratification by clinical parameters was crucial to reduce false-positive result in OA association studies, especially in GWAS studies with large-scale subjects.

Some limitations should be noted in our study. First, the number of study subjects of our study was still limited, although it was much larger than that in the previous Chinese study [16]. The sample size had a statistical power of 0.27 to detect an effect size of 1.10 with an $\alpha$-level of 0.05 for the association of the SNP rs8044769 with OA risk. Secondly, we did not find detailed allele or genotype data for rs8044769 in the Caucasian reports, so we made a meta-analysis of only Chinese data. Considering the ethnic difference, our data cannot be generalized as a global result. Further studies in Chinese and other populations are needed to evaluate the association of this SNP with OA and BMI.

\section{Conclusion}

The present study showed that the FTO polymorphism (rs8044769) was not associated with OA susceptibility in the Chinese Han population. This polymorphism was not associated with BMI in the Chinese Han population either. Higher BMI including overweight and obese is a risk factor for OA in the Chinese Han population. Further studies are necessary to identify the association of FTO with OA in different populations and to proclaim better of the OA pathogenesis.

\section{Additional files}

Additional file 1: Table S1. Genotype and allele frequencies of FTO polymorphism (rs8044769) for association analysis on OA in Han Chinese population when stratified by gender and BMI. (DOC $47 \mathrm{~kb}$ )

Additional file 2: Table S2. Genotype and allele frequencies of FTO polymorphism (rs8044769) for association analysis on BMI in Han Chinese population when stratified by gender and OA status. (DOC $44 \mathrm{~kb}$ )

\section{Abbreviations}

95\% Cl: 95\% confidence interval; BMI: Body mass index; FTO: Fat mass and obesity-associated; GWAS: Genome-wide association study; HWE: HardyWeinberg equilibrium; OA: Osteoarthritis; OR: Odds ratio; SNP: Singlenucleotide polymorphism

\section{Acknowledgements}

We thank Qiting Ge (Laboratory for Bone and Joint Diseases, Australia-China Joint Centre, Model Animal Research Center, Nanjing University, Nanjing, Jiangsu, 210009, China.) for the sample preparation and all the subjects who were enrolled in this study for the donation of their sample and clinical information.

\section{Funding}

This work was supported by the National Natural Science Foundation of China (81420108021).

\section{Availability of data and materials}

The datasets used and/or analyzed during the current study are available from the corresponding author on reasonable request.

\section{Authors' contributions}

$J D, Y P, H T, Y W$, and QJ have made substantial contributions to the conception and design, analysis and interpretation of the data, and have been involved in drafting the manuscript or revising it critically for important intellectual content. $D S, H H, Y S, Z X, D C, G Z$, and MN acquired the data and have given the final approval of the version to be published. All authors read and approved the final manuscript.

\section{Ethics approval and consent to participate}

This study was approved by the ethics review committee of the Nanjing University and conducted according to the Declaration of Helsinki principles. All participants were informed with letter of consent.

\section{Consent for publication}

Not applicable.

\section{Competing interests}

The authors declare that they have no competing interests.

\section{Publisher's Note}

Springer Nature remains neutral with regard to jurisdictional claims in published maps and institutional affiliations.

\section{Author details}

${ }^{1}$ The department of Sports Medicine and Adult Reconstructive Surgery, Drum Tower Hospital, School of Medicine, Nanjing University, 321

Zhongshan Road, Nanjing 210009, Jiangsu, China. ${ }^{2}$ Laboratory for Bone and Joint Diseases, Australia-China Joint Centre, Model Animal Research Center, Nanjing University, 12 Xuefu Road, Nanjing 210061, China. ${ }^{3}$ Department of Orthopaedics, Chinese PLA General Hospital, 28 Fuxing Road, Beijing 100853, China.

Received: 22 January 2018 Accepted: 16 March 2018

Published online: 02 April 2018

\section{References}

1. Valdes AM, Spector TD. Genetic epidemiology of hip and knee osteoarthritis. Nat Rev Rheumatol. 2011;7:23-32.

2. Killock D. Osteoarthritis: the influence of obesity on OA-does size matter or is metabolic dysfunction more important? Nat Rev Rheumatol. 2012;8:61.

3. Issa Rl, Griffin TM. Pathobiology of obesity and osteoarthritis: integrating biomechanics and inflammation. Pathobiol Aging Age Relat Dis. 2012;2: 17470.

4. Gerken T, Girard CA, Tung YC, Webby CJ, Saudek V, Hewitson KS, et al. The obesity-associated FTO gene encodes a 2-oxoglutarate-dependent nucleic acid demethylase. Science. 2007;318:1469-72.

5. Han Z, Niu T, Chang J, Lei X, Zhao M, Wang Q, et al. Crystal structure of the FTO protein reveals basis for its substrate specificity. Nature. 2010;464:1205-9.

6. Frayling $T M$, Timpson $N J$, Weedon $M N$, Zeggini $E$, Freathy RM, Lindgren $C M$, et al. A common variant in the FTO gene is associated with body mass index and predisposes to childhood and adult obesity. Science. 2007;316: 889-94.

7. Scott LJ, Mohlke KL, Bonnycastle LL, Willer CJ, Li Y, Duren WL, et al. A genome-wide association study of type 2 diabetes in Finns detects multiple susceptibility variants. Science. 2007;316:1341-5.

8. Song Y, You NC, Hsu YH, Howard BV, Langer RD, Manson JE, et al. FTO polymorphisms are associated with obesity but not diabetes risk in postmenopausal women. Obesity (Silver Spring). 2008;16:2472-80.

9. Zeggini E, Weedon MN, Lindgren CM, Frayling TM, Elliott KS, Lango H, et al. Replication of genome-wide association signals in UK samples reveals risk loci for type 2 diabetes. Science. 2007;316:1336-41. 
10. Yang J, Loos RJ, Powell JE, Medland SE, Speliotes EK, Chasman DI, et al. FTO genotype is associated with phenotypic variability of body mass index. Nature. 2012;490:267-72.

11. Zhao J, Bradfield JP, Li M, Wang K, Zhang H, Kim CE, et al. The role of obesity-associated loci identified in genome-wide association studies in the determination of pediatric BMI. Obesity (Silver Spring). 2009;17:2254-7.

12. Wing MR, Ziegler JM, Langefeld CD, Roh BH, Palmer ND, Mayer-Davis EJ, et al. Analysis of FTO gene variants with obesity and glucose homeostasis measures in the multiethnic insulin resistance atherosclerosis study cohort. Int J Obes. 2011;35:1173-82.

13. Zeggini E, Panoutsopoulou K, Southam L, Day-Williams AG, Lopes MC, Boraska $V$, et al. Identification of new susceptibility loci for osteoarthritis (arcOGEN): a genome-wide association study. Lancet. 2012;380:815-23.

14. Panoutsopoulou K, Metrustry S, Doherty SA, Laslett LL, Maciewicz RA, Hart DJ, et al. The effect of FTO variation on increased osteoarthritis risk is mediated through body mass index: a mendelian randomisation study. Ann Rheum Dis. 2014;73:2082-6.

15. Yau MS, Yerges-Armstrong LM, Liu Y, Lewis CE, Duggan DJ, Renner JB, et al. Genome-wide association study of radiographic knee osteoarthritis in North American Caucasians. Arthritis Rheumatol. 2017;69:343-51.

16. Wang $Y$, Chu M, Rong J, Xing B, Zhu L, Zhao Y, et al. No association of the single nucleotide polymorphism rs8044769 in the fat mass and obesityassociated gene with knee osteoarthritis risk and body mass index: a population-based study in China. Bone Joint Res. 2016;5:169-74.

17. Jiang Q, Shi D, Yi L, Ikegawa S, Wang Y, Nakamura T, et al. Replication of the association of the aspartic acid repeat polymorphism in the asporin gene with knee-osteoarthritis susceptibility in Han Chinese. J Hum Genet. 2006;51: 1068-72.

18. Kellgren JH, Lawrence JS. Radiological assessment of osteoarthritis. Ann Rheum Dis. 1963;22:237-55.

19. The World Health Organization. Physical status: the use and interpretation of anthropometry. Report of a WHO expert committee. World Health Organ Tech Rep Ser. 1995;854:1-452.

20. Lespasio MJ, Piuzzi NS, Husni ME, Muschler GF, Guarino A, Mont MA. Knee osteoarthritis: a primer. Perm J. 2017:21:16-183.

21. Du H, Chen SL, Bao CD, Wang XD, Lu Y, Gu YY, et al. Prevalence and risk factors of knee osteoarthritis in Huang-Pu District, Shanghai. China Rheumatol Int. 2005;25:585-90.

22. Kerkhof HJ, Meulenbelt I, Akune T, Arden NK, Aromaa A, Bierma-Zeinstra SM, et al. Recommendations for standardization and phenotype definitions in genetic studies of osteoarthritis: the TREAT-OA consortium. Osteoarthr Cartil. 2011;19:254-64

23. Loughlin J. Osteoarthritis: all types of trouble-defining $\mathrm{OA}$ in the genomicera. Nat Rev Rheumatol. 2011;7:200-1.

24. McCarthy Ml, Abecasis GR, Cardon LR, Goldstein DB, Little J, loannidis JP, et al. Genome-wide association studies for complex traits: consensus, uncertainty and challenges. Nat Rev Genet. 2008;9:356-69.

25. Todd JA. Statistical false-positive or true disease pathway? Nat Genet. 2006 38:731-3.

\section{Submit your next manuscript to BioMed Central and we will help you at every step:}

- We accept pre-submission inquiries

- Our selector tool helps you to find the most relevant journal

- We provide round the clock customer support

- Convenient online submission

- Thorough peer review

- Inclusion in PubMed and all major indexing services

- Maximum visibility for your research

Submit your manuscript at www.biomedcentral.com/submit

) Biomed Central 